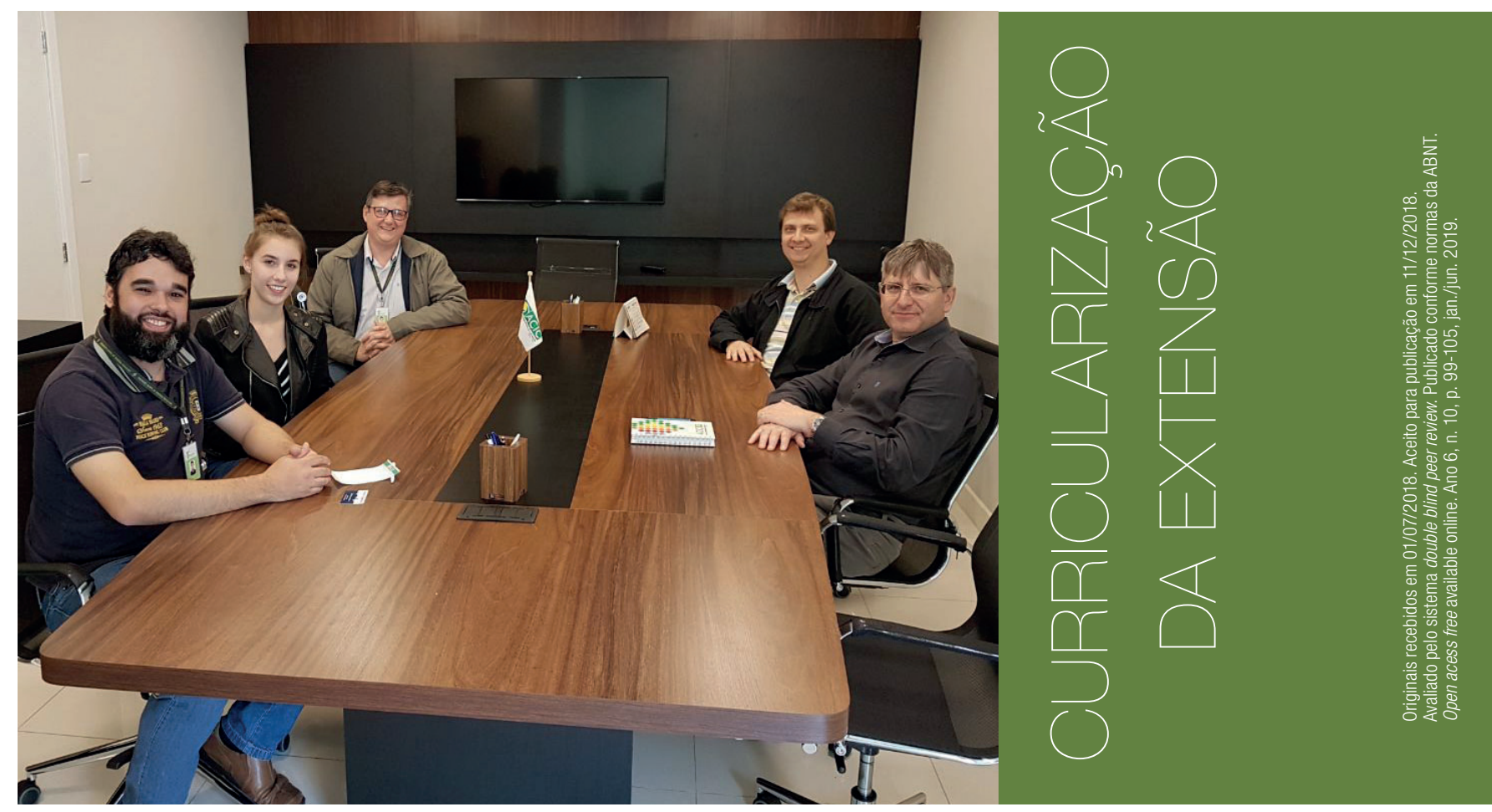

\title{
A construção do primeiro curso adequado a políticas de extensão no currículo no IFSC: planejamento pedagógico de sistemas de informação e ações iniciais
}

Egon Sewald Junior - egon.junior@ifsc.edu.br ${ }^{1}$

Greyson Alberto Rech - greyson.rech@ifsc.edu.br ${ }^{2}$

Vitor Sales Dias da Rosa - vitor.sales@ifsc.edu.br ${ }^{3}$

\section{RESUMO}

0 neologismo "curricularização da extensão" significa incorporar atividades de extensão no currículo dos cursos. 0 curso de bacharelado em Sistemas de Informação do Câmpus Caçador do Instituto Federal de Santa Catarina (IFSC) foi planejado/construído em meio à discussão das resoluções internas e definições da política de currucularização, incorporando em seus documentos tais definições. 0 presente relato tem como contribuição a narrativa do processo de planejamento, considerando as políticas institucionais e as ações desenvolvidas para viabilizar tal incorporação.

\footnotetext{
1 Doutor em Engenharia e Gestão de Conhecimento - Coordenador GT Elaboração PPC Sistemas de Informação - Docente EBTT

2 Mestre em Ensino de Ciências Exatas - Coordenador Extensão Câmpus Caçador - Docente EBTT

3 Doutor em Modelagem Computacional - Coordenador Sistemas de Informação - Docente EBTT
} 


\section{PALAVRAS-CHAVE}

Planejamento pedagógico. Curricularização. Atividades de extensão.

\section{ABSTRACT}

The neologism "extension curricularisation" means to incorporate extension activities into the curriculum of the degree's programs. The Bachelor's Degree in Information Systems at Caçador was planned/constructed amidst a series of internal rules and definitions and its definitions were incorporated into its documents. The present report is a narrative of the planning process, considering the institutional policies and as powerful actions to make feasible the incorporation.

\section{KEYWORDS}

Pedagogical Planning. Incorporation into the Program Curriculum. Extension activities.

\section{Fundamentação}

Para que o relato de experiência tenha sentido, faz-se necessária a identificação dos pressupostos legais e normativos, bem como a base de fundamentos que suportaram conceitualmente 0 desenvolvimento do planejamento pedagógico do curso e, consequentemente, influenciam diretamente nas políticas de extensão alinhadas a ele.

\subsection{Pressupostos legais e normativos}

A extensão é vista como um processo de quebra das barreiras impostas pelo muro das escolas. No âmbito do Instituto Federal de Santa Catarina (IFSC), é definida no Anexo da Resolução nº 61 de 12 de dezembro de 2016, do Conselho Superior (Consup):

Art. $1^{\circ}$ A extensão é entendida como um processo educativo, cultural, político, social, científico e tecnológico que promove a interação dialógica e transformadora entre o IFSC e a sociedade de forma indissociável ao ensino e à pesquisa (INSTITUTO, 2016b, p. 2).

Determina ainda que as atividades de extensão são aquelas "relacionadas ao compartilhamento mútuo de conhecimento produzido, desenvolvido ou instalado no âmbito da instituição e estendido à comunidade externa" (INSTITUTO, 2016b, p. 2). Por normativa determina, em seu art. $1^{0}$, determinar que os cursos superiores assegurem no mínimo 10\% da carga horária à extensão, respeitando o estabelecido no Plano Nacional de Educação (PNE) 2014-2024 (Lei no 13.005, de 25 de junho de 2014) (INSTITUT0, 2016a, p.1).

Sendo assim, o Planejamento Pedagógico do Curso (PPC) deve considerar em seu desenvolvimento $10 \%$ da sua carga horária total em atividades de extensão.

\subsection{Planejamento Pedagógico e Currículo}

0 desenvolvimento do currículo, na educação profissional, tem como objetivo proporcionar, aos alunos, competências (ZANONA, 2015) relacionadas ao mundo do trabalho, respeitando os arranjos locais (TARDIF, 2014).

0 currículo é a ligação entre a cultura e a sociedade exterior à escola e à educação; entre o conhecimento e cultura herdados e a aprendizagem dos alunos; entre a teoria (ideias, suposições e aspirações) e a prática possível, dadas determinadas condições. (SACRISTÁN, 1999, p. 61)

Assim, o currículo deve ser pensado e construído utilizando como base identificação das demandas locais, durante o planejamento do curso, ou seja, na construção do Planejamento 
Pedagógico do Curso.

0 PPC dá organização ao curso, definindo seus objetivos gerais, sua justificativa de criação e concepção de currículo e matriz. Deve considerar as estruturas internas, como divisões entre disciplinas, e externas, como fronteiras "entre as escolas e 'comunidades (profissionais e acadêmicas) produtoras de conhecimento', e entre as escolas e o conhecimento cotidiano de comunidades locais" (YOUNG, 2007, p. 1299).

Considerando esse conceito, o planejamento pedagógico do curso deve considerar a inclusão do aluno nessas estruturas externas e usa a inclusão no currículo de base para a sua concepção, aproximando o discente (e consequentemente 0 egresso) no mundo do trabalho, sem "jogá-Io" despreparado ao final do curso.

\section{Relato de experiência}

0 relato de experiência contempla a narrativa do processo de planejamento pedagógico e as primeiras ações para inclusão da extensão, considerada como parte do currículo e componente indissociável, no PPC, no âmbito do curso de bacharelado em Sistemas de Informação, no Câmpus Caçador do IFSC.

\subsection{Construção do PPC}

0 planejamento pedagógico do curso foi construído a partir de uma pesquisa de demandas, realizada com apoio da Associação Empresarial de Caçador (ACIC) e de intenções levantadas em escolas. Considerado muito pequeno, o mercado de sistemas de informação na cidade e região mostrou-se atendido (deficitariamente) por produtos e serviços de informática fornecidos por empresas de fora. No levantamento nas escolas, o uso da Tecnologia de Informação e Comunicação (TIC) no processo ensino-aprendizagem foi informalmente, apontado como deficitário.

0 curso se justifica, portanto, em alguns eixos: Desenvolvimento Econômico Regional, Incremento de Empregabilidade e Novos Negócios, Desenvolvimento Profissional, Interesse da Comunidade, Demanda de Produtos e Serviços desenvolvidos na Região e Acesso Gratuito ao Ensino. Destaca-se, com relação à extensão, a demanda de produtos e serviços e, a partir da identificação de quais deveriam ser prioridade (ainda com a pesquisa realizada em parceria com a $\mathrm{ACIC}$ ), foi construída a matriz curricular de forma a contemplar os interesses regionais.
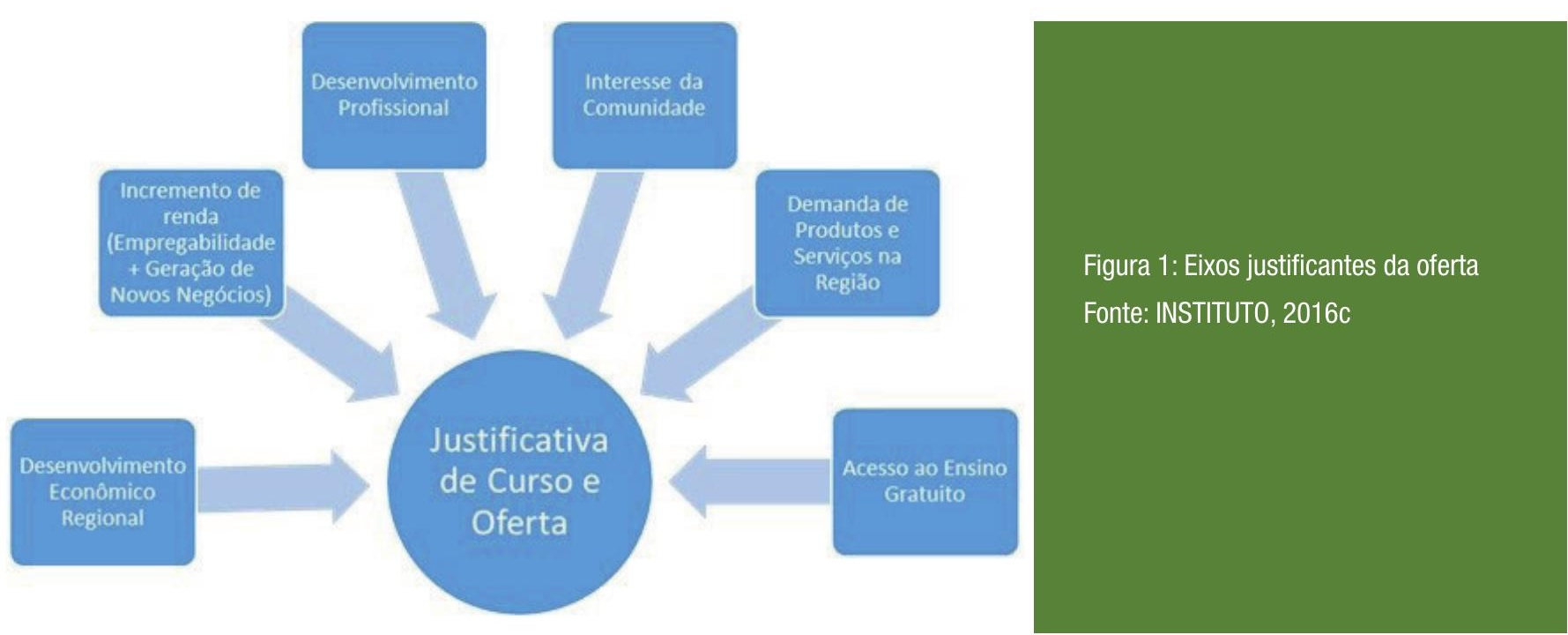

Por sua vez, a construção do PPC do curso de Sistemas de Informação se deu durante as definições da curricularização da extensão da instituição - tanto que os pareceres positivos encaminhados pelo Colegiado de Ensino, Pesquisa e Extensão (Cepe) da instituição foram 
aprovados e encaminhados para o Conselho Superior (Consup) na mesma data, após reunião do CEPE realizada no dia 30 de junho de 2016. Em cada interação com a Diretoria de Extensão (Direx), na estrutura da Reitoria, sugestões foram dadas e discussões com a grupo de trabalho de elaboração do PPC discutia sobre as estratégias de, em um curso de 3.400 horas (carga horária igual ao valor referência), dedicar $10 \%$ a atividades de extensão.

Ao deparar com a normatização das atividades, o Grupo de Trabalho, ainda com certos preconceitos quanto à "reserva" de carga horária, identificou dificuldades para incluir as 340 horas de atividades de extensão. 0 grupo reunia-se quinzenalmente em reuniões presenciais, além de trabalhos delegados a cada servidor e consolidados pelo coordenador do GT.

0 Grupo de Trabalho decidiu, então, usar um mix das estratégias sugeridas pela Direx, observando sua possível relação prática com as demandas identificadas na comunidade, resultado observado no PPC do curso:

1. Trabalhos de Conclusão de Curso: 2 componentes curriculares totalizando 240 horas, no qual 0 aluno deverá aplicar os conhecimentos adquiridos durante 0 curso para o desenvolvimento de pesquisa e sua aplicação sob forma de extensão, por meio de atividades com objetivo a interação com empresas de bens e serviços diversos e demais instituições, fomentando a aplicação e resolução de problemas de ordem técnica, caracterizando uma típica atividade de extensão. 0 trabalho de Conclusão de Curso I totaliza 60 horas de extensão, contemplando a identificação da demanda a ser trabalhada. A unidade Trabalho de Conclusão de Curso II totaliza 120 horas de extensão, integrada com a pesquisa acadêmica (40 horas), contemplando refinamento da demanda e aplicação da solução junto à comunidade e/ou empresas.

2. Atividades Complementares: integralização de 120 horas, durante 0 período de estudos de atividades complementares, conforme definições em regulamentação em anexo, onde no mínimo 60 horas devem ser compostas por atividades de extensão registradas na Direx, conforme normativas e regulamentos sobre a extensão no IFSC;

3. 80 horas de extensão presentes, na matriz curricular, com a unidade "Projeto Extensão l", devendo ser desenvolvidas em atividades de extensão registradas na Direx, conforme normativas e regulamentos sobre a extensão no IFSC; (INSTITUTO, 2016c)

Para que fosse possível, a defesa dada quanto à parcela do Trabalho de Conclusão de Curso corresponder a atividades de extensão se deu a partir da regulamentação do TCC, devendo este envolver a comunidade externa e tratar de um trabalho aplicado, abrangendo, de forma indissociável, o ensino, a pesquisa (fase de construção da solução) e a extensão (fase de identificação do problema e da sua aplicação na comunidade externa).

Houve ainda a determinação de no mínimo 50\% das atividades complementares a serem integralizadas pelos estudantes (equivalente a 60 horas), bem como o desenvolvimento de uma unidade curricular, na quinta fase do curso, com 80 horas desenvolvida totalmente com atividades de extensão, conforme regulamentação.

0 grupo de trabalho, além de atender os marcos regulatórios da instituição, entendeu que, como resultado, o discente deve se aproximar mais da comunidade externa e do ambiente de trabalho, quando comparado com cursos sem tal dedicação de carga à extensão, e isso facilita o cumprimento da missão de incluir através da educação profissional e tecnológica. Essa percepção foi construída durante o processo de planejamento do curso.

0 curso foi apreciado pelo Cepe em três reuniões, durante 0 ano de 2016, onde foram sugeridas melhorias (inclusive quanto a atividades de extensão), obtendo parecer favorável no dia 30 de junho de 2016, com a resolução Cepe n 32/2016. 0 curso foi aprovado e teve oferta autorizada pelo Consup, através da Resolução $n^{0}$ 30, de 27 de julho de 2016.

Após sua aprovação, iniciou-se trabalho para ofertar o curso e identificar possíveis atividades de extensão. 
0 curso de Sistemas de Informação iniciou sua oferta em 2017 e tem alunos em duas turmas ( $1^{\circ}$ e $2^{\circ}$ ano de curso). Ainda não alcançou a $5^{\text {a }}$ fase do curso, com a unidade curricular de Projeto de Extensão I. Em sua matriz, delega carga mínima de atividades complementares a serem integralizadas em 120 horas, sendo, no mínimo, 60 horas em atividades de extensão.

A geração de oportunidades de extensão, considerando o protagonismo discente nas ações, com objetivo de aproximar o estudante do ambiente externo e possibilitar a aplicação de seus conhecimentos, foi iniciada desde o primeiro semestre. Tal tarefa é realizada sob orientação e acompanhamento da coordenação do curso e da coordenação de extensão do Câmpus Caçador. 0 PPC foi construído com base em demandas reais e buscar atendê-las durante 0 curso proporciona ao aluno uma melhor capacitação para enfrentar o ambiente de trabalho. Nos contatos para a construção do PPC, empresas, a secretaria municipal de educação e a ACIC colocaram-se como parceiras para a inserção dos alunos no ambiente de trabalho, através de atividades de extensão.

Desde o primeiro dia de aula (junto à aula magna), ao receber os alunos e explanar sobre a estrutura do curso, buscou-se sensibilizar os alunos ao mostrar as oportunidades de crescimento com a aplicação dos conhecimentos no ambiente externo, com foco na indissociabilidade entre ensino, pesquisa e extensão. Tal sensibilização era feita a todo momento pelos coordenadores do curso que atuaram (e aquele que continua atuando) com as turmas.

No primeiro ano do curso, foram criadas duas iniciativas de extensão: (1) Empresa Júnior e (2) Aprendizagem de matemática e lógica com construção de jogos no Scratch.

0 projeto da Empresa Júnior foi aprovado no ano de 2017 e recebeu o número PJ266-2017, sob coordenação do professor Egon Sewald Junior. Foram feitas diversas reuniões com entidades e empresas em busca de projetos, porém as demandas iniciais dessas empresas, que aceitaram incorporar uma equipe de estudantes, oportunizando uma aplicação de conhecimentos trabalhados no curso, buscavam ações que, devido ao fato de o curso estar em seu primeiro ano, ainda não tinham sido desenvolvidos - a exemplo de projeto de melhoria de desempenho em banco de dados de uma rede importante de supermercados, o que seria impossível porque os alunos só teriam a unidade curricular de Banco de Dados no segundo ano.

Diferentemente da maioria dos projetos de empresas juniores, o objetivo desta era a formação de clusters orientados a interesses, dando oportunidades para um maior número de alunos, conforme interesse de formação; assim, um projeto na área de redes, por exemplo, seria aproveitado por grupo de alunos com interesse na área, assim como aqueles projetos relacionados ao desenvolvimento de softwares, por outro grupo, conforme interesse. Em 2018, o projeto foi renovado, mantendo estruturas, porém alterando os servidores participantes, considerando as remoções de professores da área de Tecnologia de Informação e Comunicação, captando novos projetos e formando grupos de interesse. Ainda, com objetivo de possibilitar participação de maior número de alunos, o câmpus vem lançando cursos de curta duração (ensino) que podem antecipar a participação de estudantes nas atividades da empresa júnior e de extensão.

0 projeto de ensino de matemática e lógica utilizando Scratch teve início em 2017, com a participação de um grupo de 10 estudantes, que formaram um grupo de estudos e identificaram defasagem de aprendizado no ensino fundamental e procuraram a utilização de TIC. A ferramenta Scratch possibilita desenvolver a criatividade, o raciocínio e 0 aprendizado de conteúdos de maneira inovadora, por meio de trabalho colaborativo e pesquisa. Essa ferramenta possibilita a criação de jogos e animações interativas que podem ser disponibilizadas em portal web. Durante a construção dos jogos e animações estuda-se o desenvolvimento do processo de aprendizagem da matemática e do raciocínio lógico com o objetivo de melhorar os conhecimentos dos educandos do Ensino Fundamental da rede pública. Em 2017, como resultado do grupo de estudos da ferramenta, já houve impacto na comunidade externa, com oficinas realizadas na Semana Nacional de Ciência e Tecnologia, com 0 atendimento de cerca de 100 crianças e jovens. A oficina foi ministrada totalmente por alunos e serviu como "evento-teste" para sua aplicação na comunidade externa e aplicação em escolas do município. 


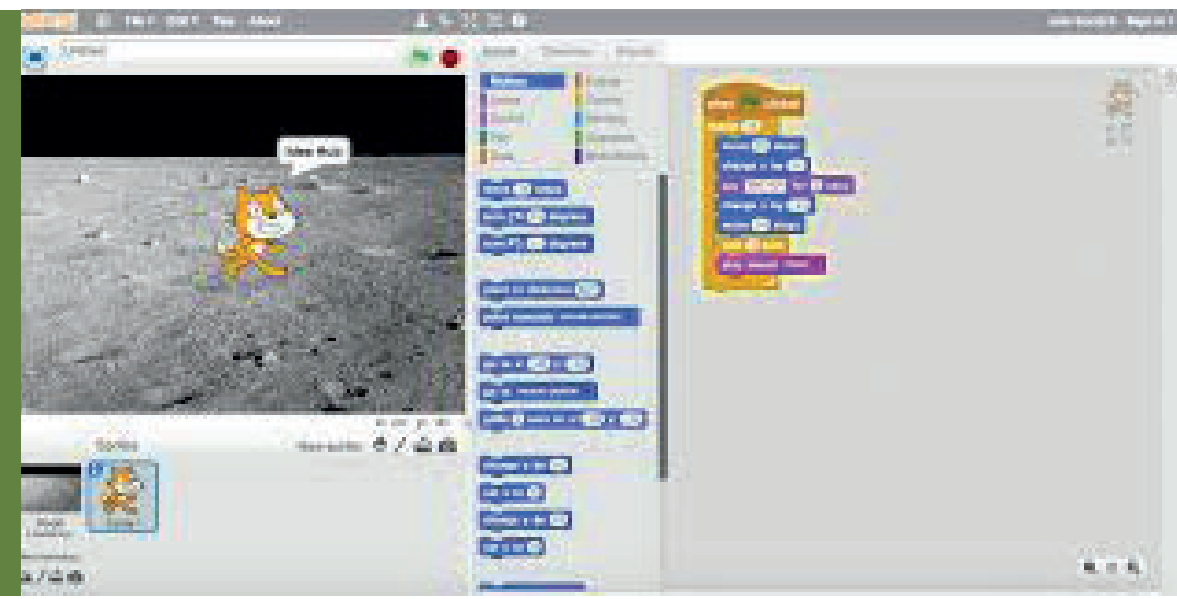

0 projeto foi consolidado e aprovado sob número PJ233-2018, sob coordenação do professor Vitor Sales. Em sua documentação, o projeto autodefine sua atuação: "Desenvolver-se-á uma extensão com princípios dialéticos, respeitando os conhecimentos já adquiridos pelos estudantes e estimulando avanços na qualidade dos saberes dos envolvidos na extensão. Os educandos serão sujeitos ativos no processo de ensino-aprendizagem, aprimorando seus conhecimentos construindo jogos e animações a partir de programas no Scratch". Ainda define seus passos, determinando que inicialmente serão discutidas com os bolsistas/extensionistas as etapas da extensão e uma abordagem teórica da linguagem que será trabalhada. Além de discutir textos que oportunizarão compreender a necessidade da extensão como ferramenta de aprendizagem, será aprofundada também em bibliografias a importância e necessidade do trabalho colaborativo para 0 desenvolvimento social. Em seguida, serão apresentados projetos que já foram desenvolvidos em Scratch, estudando as ferramentas de que a linguagem dispõe, motivando os educandos e mostrando o potencial da linguagem. Ao final, os envolvidos desenvolverão produções como jogos, vídeos etc., nas quais abordarão ligações com conteúdo da matemática do Ensino Fundamental. Cabe ressaltar que a simplicidade da linguagem de programação Scratch permite facilmente elaborar jogos de RPG, plataforma etc. No desenvolvimento desses jogos, em oficinas semanais, os conteúdos de matemática são necessários possibilitando 0 aprendizado ativo a partir da investigação e busca desses saberes. Ao concluir a extensão os envolvidos apresentarão seus projetos e colocarão na plataforma web do Scratch.

0 câmpus busca sensibilizar os discentes sobre a participação em todos os projetos de extensão, no que diz respeito à formação de cidadania e de competências humanas e sociais. Outros projetos diretamente relacionados à aplicação do ensino de Sistemas de Informação estão iniciando, como "Aplicação de algoritmos de aprendizagem de máquina na análise de dados de violência contra a mulher em Caçador/SC" e "Privacidade e Segurança da Informação para Crianças e Adolescentes". Desta forma, o câmpus, a partir da coordenação do curso e coordenação de extensão, busca atender a todos os estudantes, sensibilizando-os quanto à necessidade de aproximação do meio externo, aos ganhos em conhecer e aplicar os conhecimentos desenvolvidos nas atividades de ensino e pesquisa, de forma associada, durante o curso, preparando uma inclusão melhor e mais efetiva, quando tornar-se egresso.

\section{Referências}

Instituto Federal de Santa Catarina. Conselho Superior. Resolução CONSUP $\mathbf{n}^{0} \mathbf{4 0}$, de $\mathbf{2 9}$ de agosto de 2016. Aprova as diretrizes para inclusão das atividades de extensão nos currículos dos cursos de graduação do IFSC e dá outras providências. Florianópolis, 2016a.

Conselho Superior. Resolução CONSUP nº 61, de 12 de dezembro de 2016.

Regulamenta as Atividades de Extensão no IFSC. Florianópolis, 2016b.

Planejamento Pedagógico do Curso Sistemas de Informação. Caçador: 
TARDIF, M. Saberes docentes e formação profissional. Petrópolis. Vozes. 2014.

SACRISTÁN, J.G. Poderes instáveis em educação. Porto Alegre: Artmed, 1999

SCRATCH Brasil, [201?]. Disponível em: http://www.scratchbrasil.net.br/. Acesso em: 20 jun 2018.

YOUNG, Michael F. D. Para que servem as escolas? Educação \& Sociedade, v. 28, n.

101. Campinas: set./dez. 2007. Disponível em https://www.cedes.unicamp.br/publicacoes/ edicao/112. Acesso em: 20 jun 2018.

ZANONA, Roberta Castaldoni. Educar por competências na formação profissional. São Paulo: Centro Paula Souza, 2015. 